\title{
Progress in Additive Manufacturing
}

\author{
EDWARD D. HERDERICK ${ }^{1,2}$ \\ 1.-GE Corporate Supply Chain and Operations, Cincinnati, OH, USA. 2.-e-mail: edward.herderick@ \\ ge.com
}

Additive manufacturing ( $\mathrm{AM}$ ) is among the fastest growing ${ }^{1}$ and most talked about manufacturing technologies on the planet. ${ }^{2,3}$ It is providing diverse opportunities for new product design and manufacturing. At GE, efforts such as the additively produced LEAP engine fuel nozzle ${ }^{4}$ and low-pressure turbine blade manufacturing ${ }^{5}$ are examples of how GE Aviation is leveraging these technologies in innovative ways. These are just a few illustrations of how AM is changing the manufacturing landscape and many others are described in the articles that follow.

This rapid growth and investment poses several questions for the minerals, metals, and materials community: What exactly is "additive manufacturing?" Why has it captured the manufacturing industry imagination? How can the TMS community of materials and process technologists and leaders contribute to its growth and implementation?

At its core, AM is a suite of technologies that "build" components using digital model data. The ASTM Committee F42 on AM Technologies has defined seven different process routes as being part of the field of AM. ${ }^{6}$ Each process has its own unique benefits and challenges that derive from the thermal and chemical processing cycle and the resulting microstructure. ${ }^{7-9}$ Any discussion of the technology needs to take into account the details of the resulting materials microstructure, surface roughness, and ability to maintain engineering tolerances, as well as implementation details about reliability and cost, and potential supply chain issues.

The industrial excitement around this suite of processes is being driven by its capacity for empowering designers to focus on designing components for functionality rather than limitations

Edward D. Herderick is the guest editor for the Process Technology and Modeling Committee of the TMS Materials Processing \& Manufacturing Division, and coordinator of the topic Progress in Additive Manufacturing in this issue. of conventional processes such as casting, brazing, or forming processes. Furthermore, it is now enabling a whole new paradigm of rapid testing and product introduction wherein functional metal prototypes can be used for testing of individual components and manufacturing assembly processes (e.g., joining, forming, or machining). Using AM means product development cycles do not have to rely on traditional methods for manufacturing metallic prototypes, which can take months to produce.

This leads to the key question: How can the minerals, metals, and materials community contribute to responsible, accelerated growth given the context of where the field is today? The key to industrial implementation for manufacturing technologies is a thorough understanding of the synergistic interaction of materials and processes. ${ }^{10}$ For AM, there are currently only a handful of materials and processes that are well understood, such as the previously mentioned laser powder-bed fusion of cobalt chrome and electron beam powder-bed fusion of titanium aluminide. To realize the full potential of AM, further maturation of the processing-structure-properties linkages will be required in a broader set of metal alloys and for many more processing approaches. When that happens, AM adoption will accelerate as industrial designers become empowered to select tailored material and process combinations that drive performance improvement for demanding applications.

This special topic, Progress in AM, strives to meet that challenge by presenting a collection of articles that cover a broad spectrum of material systems and AM processing approaches including original research topics and application reviews. To download any of the articles, follow the URL: http://link.spring er.com/journal/11837/67/3/page/1 to the table of contents page for the March 2015 issue (Vol. 67, No. 3).

In "Metallurgical and Mechanical Evaluation of 4340 Steel Produced by Direct Metal Laser Sintering," by Elias Jelis, Matthew Clemente, Stacey Kerwien, Nuggehalli M. Ravindra, and Michael R. Hespos, the authors present new work on the 
processing and mechanical properties of a ferrous alloy produced using $\mathrm{AM}$ and compare it with wrought material.

"Additive Manufacturing of Al-12Si Alloy via Pulsed Selective Laser Melting," by R. Chou, J. Milligan, M. Paliwal and M. Brochu, presents an enhanced processing approach to improve the mechanical properties of aluminum alloys produced via laser powder bed fusion AM.

"Influence of Test Orientation and Build Direction on Fracture and Fatigue Crack Propagation Behavior of as-deposited EBAM Ti-6Al-4V," by Mohsen Seifi, Matt Dahar, Ron Aman, Ola Harrysson, Jack Beuth, and John Lewandowski, documents processing effects on fracture toughness and fatigue crack growth behavior of Ti-6Al-4V produced via electron beam powder-bed fusion.

Li Yang, Ola Harrysson, Denis Cormier, Harvey West, Haijun Gong, and Brent Stucker present a review of an approach to implement enhanced design using powder bed fusion and identify areas for process improvement in "Metal Cellular Structures with Additive Manufacturing: Design and Fabrication."

"Friction-Stir Additive Manufacturing: Route to High Structural Performance" presents a strategy for developing AM materials technologies and then moves to demonstrate a solid state process that could be used for large aerospace or vehicle structural components. In their article, S. Palanivel, H. Sidhar, and R.S. Mishra describe an approach that combines the solid-state microstructure formed using friction stir with the shape making capability of AM.

In "Laser Hot Wire Process: A Novel Process for Near Net Shape Fabrication for High-Throughput Applications," results by Michael Kottman, Shenjia Zhang, James McGuffin-Cawley, Paul Denney, and Badri K. Narayanan are presented for a ferrous alloy, carbide composite, and light metal alloy using a wire-based AM approach.

In "Mechanical Properties and Microstructural Features of Direct Laser-Deposited Ti-6Al-4V," Linkan Bian, Scott M. Thompson, and Nima Shamsaei review the current literature for laserblown powder manufacturing of titanium alloys and provide views on the investigation of fatigue properties and modeling approaches.

Hazman Hasib, Ola L.A. Harrysson, and Harvey West, II identify a key postprocessing item and present a strategy for removing powder from AMprinted cellular structures in "Powder Removal from Ti-6Al-4V Cellular Structures Fabricated via Electron Beam Melting."
"Applications of Metal Additive Manufacturing in Veterinary Orthopedic Surgery," presented by Ola L.A. Harrysson, Denis J. Marcellin-Little, and Timothy J. Horn, includes a review of applications for AM in veterinary medicine and is an excellent foundation for inspiring the use of this technology for other medical implants.

Mark Norfolk and Hilary Johnson present a unique use of AM in their article, "Solid-State 3D Printing of Metal Heat Exchangers." This work shows an emerging AM technique where metal foils are ultrasonically bonded to form complex structures, otherwise difficult to manufacture.

In "Binder-Jetting-A Novel Solid Oxide Fuel Cell Fabrication Process and Evaluation," Guha Manogharan, Meshack Kioko, and Clovis Linkous present work on fabrication of ceramic oxide fuel cell components using a multistep AM approach.

In the final article in the series, W. Xu, S. Sun, J. Elambasseril, Q. Liu, M. Brandt, and M. Qian present work on "Ti-6Al-4V Additively Manufactured by Selective Laser Melting with Superior Mechanical Properties," where microstructure and corresponding mechanical properties, can be controlled through processing parameters.

This is truly an exciting time for the materials and manufacturing community as many demanding applications are beginning to present themselves as candidates for new technology development. I hope that the reader enjoys this collection of articles and that they inspire your own future research and development efforts in AM.

\section{REFERENCES}

1. Wohler's Associates Inc., $3 D$ Printing and Additive Manufacturing State of the Industry Annual Worldwide Progress Report (Fort Collins, CO: Wohler's Associates Inc., 2014).

2. S.F. Jacobsen, Hype Cycle for Leaders of Manufacturing Strategies (Ridgefield Park, NJ: Gartner Inc., 2013).

3. "Print me a stradivarius," The Economist, 10 February 2011.

4. World's first plant to print jet engine nozzles in mass production, GE Reports, 15 July 2014, www.gereports.com/post/ 91763815095/worlds-first-plant-to-print-jet-engine-nozzlesin.

5. This electron gun builds jet engines, GE Reports, 17 August 2014, www.gereports.com/post/94658699280/this-electrongun-builds-jet-engines.

6. ASTM F2792-12a, Standard Terminology for Additive Manufacturing Technologies (2012).

7. E.D. Herderick, Materials Science and Technology Proceedings (Hoboken, NJ: Wiley, 2011), pp. 1413-1425.

8. W.E. Frazier, J. Mater. Eng. Perf. 23, 1917 (2014).

9. L. Robinson and J. Scott, JOM 66, 2194 (2014).

10. R. Schafrik and R. Sprague, Key Eng. Mater. 380, 113 (2008). 